\title{
MODELLING INFILTRATION ON GRAVEL BEACHES WITH AN XBEACH VARIANT
}

\author{
Mohamad H. Jamal ${ }^{1,2}$, David J. Simmonds ${ }^{1}$, Vanesa Magar ${ }^{1}$, Shunqi Pan ${ }^{1}$
}

Coarse-grained beaches are particularly prevalent in the UK, composed of accumulations of either gravel, or mixed sand and gravel sediments. Understanding and predicting their morphological behaviour in response to short-term and long-term forcing has been the subject of recent research. Despite the focus on sandy beaches, it is important to understand that the balance of processes that govern different behaviour between sandy and gravel beaches. In this study we show how a public domain numerical model, XBeach, developed for sandy environments (Roelvink et al., 2009) can be modified for use in predicting the cross-shore profile changes of gravel beaches. Improvements investigated here include: use of Lagrangian interpretation of velocity in place of Eulerian for driving sediment movement; incorporation of Packwood's (1983) pragmatic model of infiltration in the unsaturated area of the swash region; introducing of new morphological module based upon Soulsby's (1997) sediment transport equation for waves and currents. These changes are suggested in order to significantly improve the application of this model to gravel beaches, especially with regard to swash velocity asymmetry which is responsible for development of the steep accretionary phase steep berm above waterline. The results from the model agree well with the measured experimental data and improve upon the results presented by Pedrozo-Acuña et al. (2006).

Keywords: gravel beach; infiltration; sediment transport; XBeach

\section{INTRODUCTION}

Coarse-grained beaches are an important form of natural coastal defence. They are particularly prevalent in the UK, where examples of both gravel, and mixed - sand and gravel — are prevalent. Understanding and predicting their morphological behaviour in response to short-term and long-term forcing has been the subject of recent research. Coarse-grained beaches may include both gravel and mixed sand and gravel beaches which can exhibit intermediate morphology or separate lower sandy terrace and steeper upper shingle berm (Figure 1). Figure 2 shows illustrative profiles for gravel beaches during accretion.

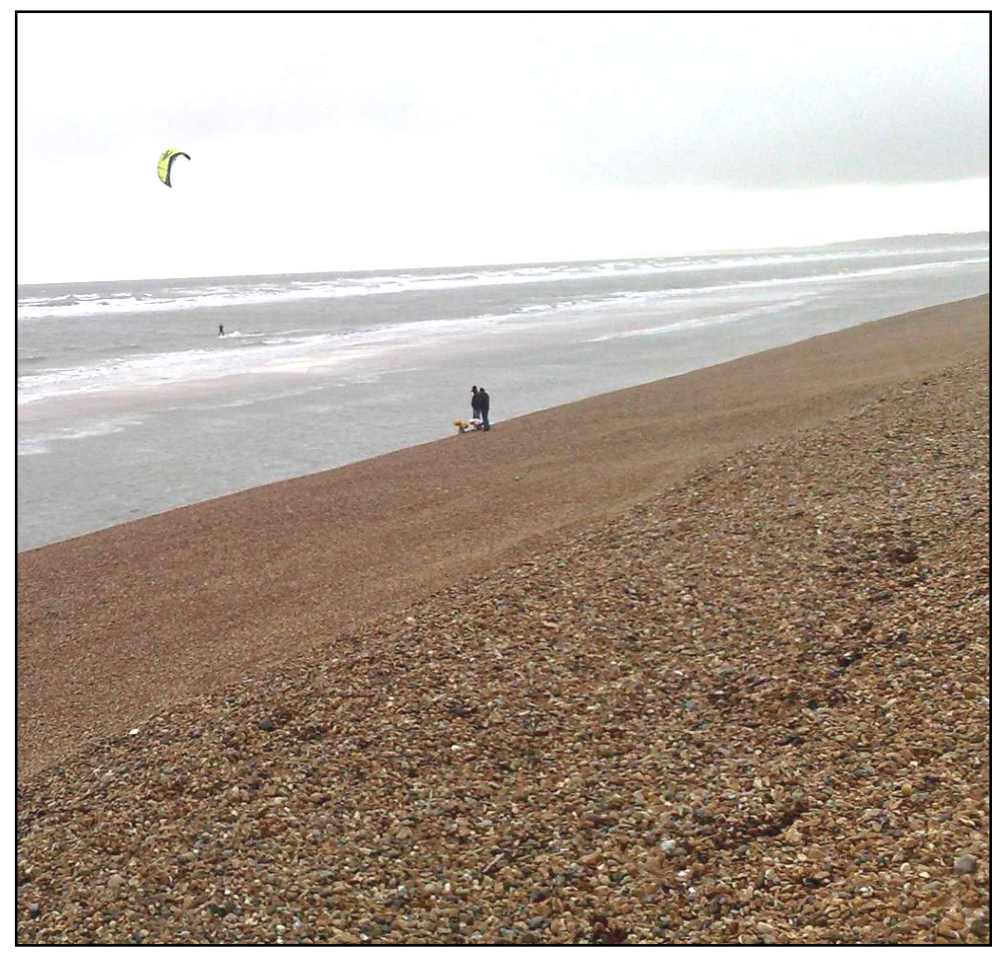

Figure 1: Accretionary berm on coarse-grained beach (Milford-On-Sea, UK).

${ }^{1}$ Coastal Engineering Research Group, University of Plymouth, Drake Circus, PL4 8AA, United Kingdom

${ }^{2}$ Faculty of Civil Engineering, Universiti Teknologi Malaysia, 81310 Skudai, Johor, Malaysia 


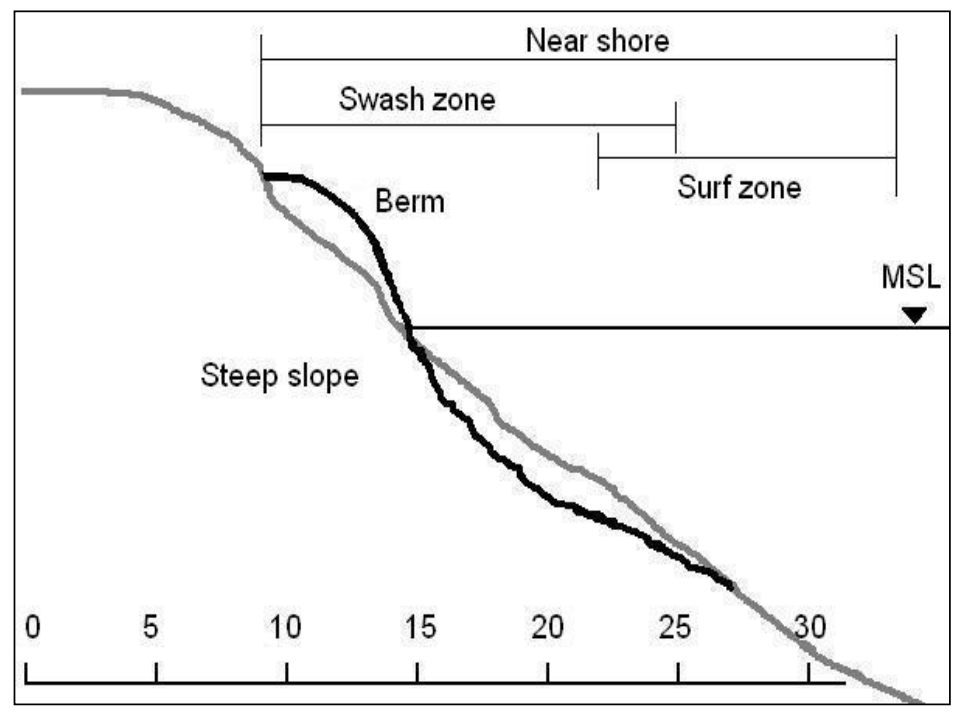

Figure 2: Formation of accretionary berm (black line) on gravel beach.

There are several factors which differentiate the morphological change between sandy beaches and gravel beaches such as the beach slope and grain properties. Permeability is one of the significant factors influencing morphological change on gravel beaches (e.g. Butt et al., 2001, López de San Román-Blanco, 2003 and Pedrozo-Acuña, 2005) which is determined by porosity, sediment size and grading. Permeability on the beach will cause water flows in and out through the beach face and becomes more significant on highly permeable beach. This process is called in/exfiltration. Therefore, in this paper, the effects of infiltration on the gravel beach profile evolution will be studied, and an improved sediment transport formulation will be evaluated that reflects the different mode of sediment movement of heavier gravel compared with sand. The fall velocity of the sediment helps to determine whether the sediment is transported by bed load or suspended load (Reeve et al., 2004 and Lawrence, 2005). On gravel beaches, whilst intermittent suspension is possible, the predominant mode is rolling, saltation and sheet flow. Hence the use of a bed load formulation is more apposite.

\section{MODELLING GRAVEL BEACH DYNAMICS}

The complexity of coastal processes makes it difficult to predict the morphological response to changing wave conditions and water levels accurately. In general, during swell conditions, the impetus for cross-shore sediment transport over coarse-grained beaches is onshore in the swash zone driven by asymmetry in flow velocity. This, increases the beach volume, steepens the beach face and raises the crest elevation (Austin, 2005). During periodic extreme storm events, larger, more energetic waves saturate the beach face and create significant erosion as the asymmetry is reduced.

Several modelling approaches of varying complexity have been reported. These include Powell's (1990) parametric modelling approach and the process-based approach of Pedrozo-Acuña (2005). Whilst the latter physics-based approach is intuitively more satisfying, problems persist associated with instability as the bed steepens and data requirements over longer timescales. The challenge is to minimise model complexity, increase stability yet reproduce and explain observation in sufficient detail. Pedrozo-Acuña et al. (2006) showed that using a non-linear Boussinesq model (COULWAVE) coupled to a reductivist Meyer-Peter \& Muller sediment transport formulation it was possible to obtain good predictions of large scale laboratory measurements profile change for coarse sediments. However, this required the ad-hoc introduction of separate transport efficiencies for up-rush and backwash. This can be interpreted as an encapsulation of several sub-processes associated with infiltration of water into the porous beach-face and accelerated flow post-breaking. These reduce shear stress and transport efficiency during backwash whilst causing an increase in the uprush.

In the swash zone, infiltration on the uprush creates sediment stabilisation and thinning of the fluid boundary layer; exfiltration on the backwash destabilizes sediment and causes thickening of the boundary layer (Butt and Russell, 2000, Karambas, 2003). Butt et al. (2001) stressed that flows that infiltrate the 
beach cause greater deposition during uprush. Reduction of the backwash volume and duration will lower the flow velocities during rundown (Elfrink and Baldock, 2002). This effect is minor on sandy beaches but very significant on gravel beaches which exhibit greater permeability.

\section{THE NEED FOR AN XBEACH VARIANT}

The open-source coastal and dune erosion model XBeach v12 was used as a baseline model in this study. This model has proven to be a robust and widely used model for morphological studies on sandy beach and dune erosion (e.g: Roelvink et al. 2009 and Van Thiel de Vries, 2009). Briefly, short wave propagation is obtained from the Wave Action Balance Equation (WABE) which then used to force terms in the Non-Linear Shallow Water Equation (NLSWE). In the original version, the Eulerian frame velocities $\left(u_{E}\right)$ are used to drive the sediment movement calculated from the Lagrangian velocities $\left(u_{L}\right)$ obtained from NLSWE. Equation 1 and 2 shows how the approximation is implemented in the model. The model uses this approximation to include the effects of return flow on sandy dune erosion and beach profile evolution.

$$
\begin{aligned}
& u_{E}=u_{L}-u_{S} \\
& u_{S}=\frac{E_{w} \cos \theta}{\rho h c}
\end{aligned}
$$

where, $u_{s}$ is the stokes drift, $E_{w}$ is wave energy, $\rho$ is water density, $h$ is water depth, $\theta$ is wave angle with respect to $x$-axis and $c$ is wave celerity.

The Van Rijn formulation is used in the model to calculate the sediment transport. A full description of this model is beyond the scope of this paper but see Roelvink et al. (2009) and Van Thiel de Vries (2009). It should be stated that the aim here is to obtain a robust tool with which to examine coarse grained beach behaviour. It should therefore sufficiently encapsulate the balance of near-shore processes that sufficiently dictate the behaviour of these environments (as opposed to, for instance, sandy beaches). Thus, to begin, we demonstrate the need for adapting the XBeach code for coarse grained beach applications.

$\mathrm{XBeach}$ is formulated as a $2 \mathrm{DH}$ model. However this research considers the cross-shore profile change of a beach under 1DH environment. Thus the incoming wave direction is set perpendicular to the beach. Also, for the purpose of this study, we re-use the data from López de San Román-Blanco et al. (2006) experiment in the large scale experiment (GWK) in Hannover, Germany (2002) employed by PedrozoAcuña et al. (2006). Figure 3 shows a cross section of the beach installed in the flume. The data used here in the numerical experiment are taken from the "test 1 (gravel)" which comprised: waves of height $0.6 \mathrm{~m}$, period 3.22s; test interval of 500 waves; initial beach slope of 1:8; gravel of $D_{50} 0.021 \mathrm{~m}$.

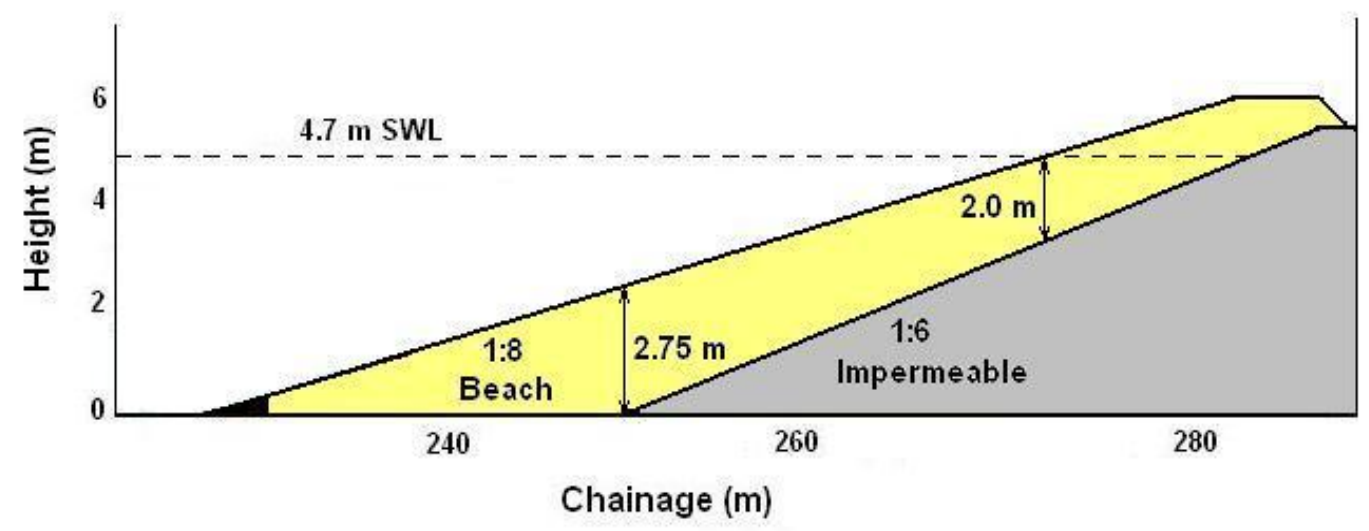

Figure 3: Schematic of gravel beach in GWK experiments.

We briefly present the unmodified XBeach v12 simulation for a gravel beach as shown in Figure 4. We found that the volume changes along the profile are very small. This is probably due to the use of the Van Rijn total sediment transport equation (bedload and suspended load) which is known to be applicable to sand with sediment size below $2 \mathrm{~mm}$. Even though the change is small it can be seen that sediment is moving offshore, eroded from above the still water line $(\mathrm{SWL}$, elevation $=0)$. This pattern is opposite to 
that of the typical evolution of an initially flat gravel beach profile illustrated previously in figure 2 . It is believed that the effect from the return flow assumption in the model contribute to the movement of sediment away from the shore. There is evident in the velocity envelope (Figure 5) obtained from the maximum offshore and onshore velocities for 500 waves. This can be seen to be highly skewed offshore, a feature exaggerated by use of the Eulerian velocity that helps to mimic the effects of undertow in the model. Hence offshore movement of sediment is enhanced.

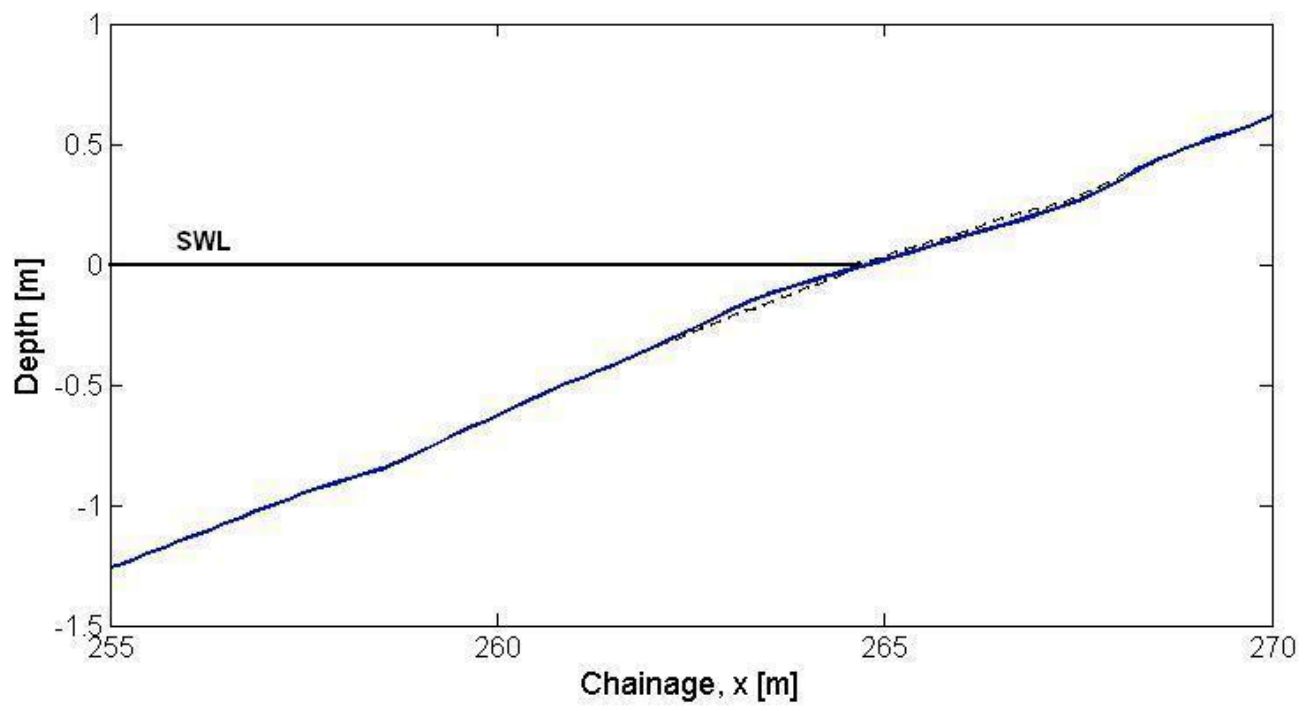

Figure 4: Simulation using unmodified XBeach v12: initial beach profile (dashed); profile after 500 waves (blue).

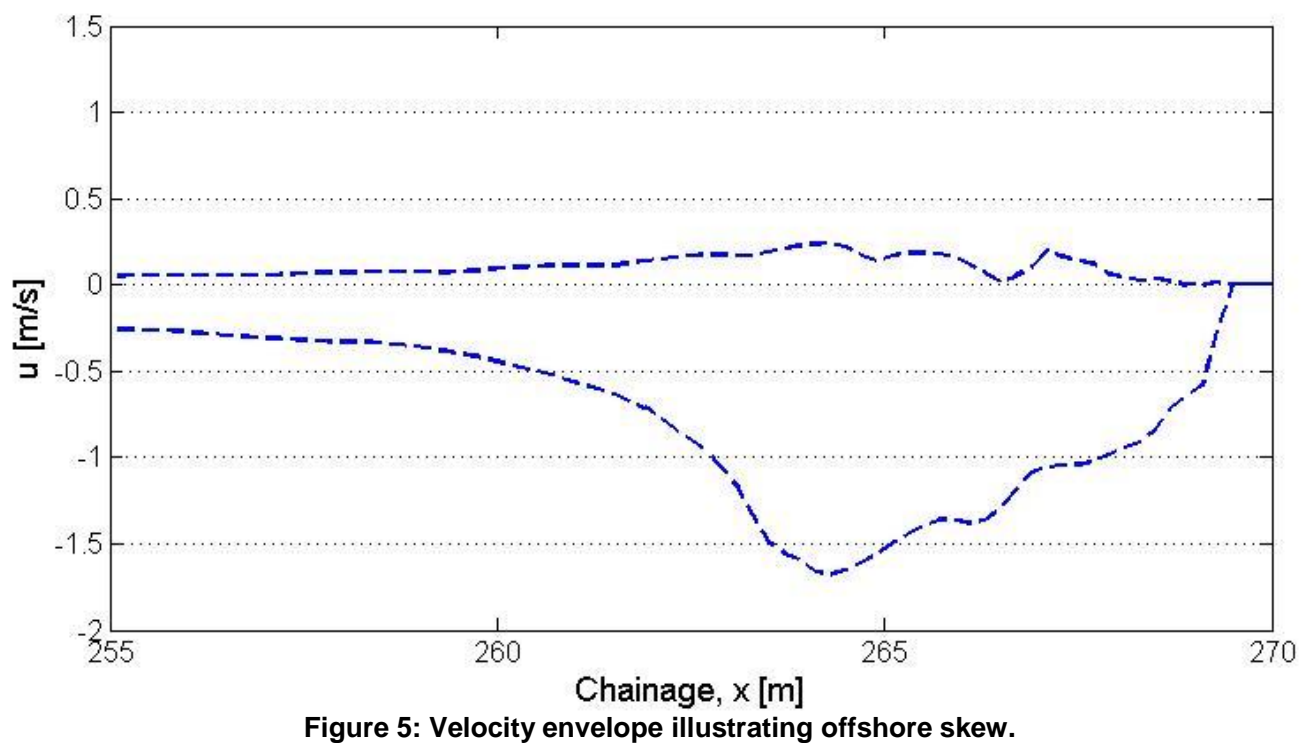

Therefore, several modifications will be presented in the next section that improves the performance of XBeach for predicting gravel beach profile dynamics.

\section{PREDICTION OF GRAVEL BEACH PROFILE EVOLUTION}

The effects of several modifications to this model are now presented.

\section{Sediment Transport Formulation}

Firstly, a new morphological module was implemented in the XBeach v12 to incorporate a more suitable sediment transport formulation. On gravel beaches, bedload is the dominant mode of transport (Soulsby, 1997 and Reeve et al., 2004), thus the Soulsby wave dominated, wave-current equation for 1D case is employed in place of the Van Rijn equation. 


$$
\begin{aligned}
& \Phi_{x 1}=C \theta_{m}^{1 / 2}\left(\theta_{m}-\theta_{\beta c r}\right) \quad \text { for } \quad \theta_{m}>\theta_{\beta c r} \\
& \Phi_{x 2}=C(0.9534+0.1907 \cos 2 \phi) \theta_{w}^{1 / 2} \theta_{m}
\end{aligned}
$$

Where $\Phi_{\mathrm{x}}$ is the maximum between $\Phi_{\mathrm{x} 1}$ and $\Phi_{\mathrm{x} 2}$

$$
\begin{aligned}
& \theta_{\text {max }}=\sqrt{\left(\theta_{m}+\theta_{w} \cos \phi\right)^{2}+\left(\theta_{w} \sin \phi\right)^{2}} \\
& \Phi_{x}=0 \quad \text { if } \quad \theta_{\text {max }} \leq \theta_{\beta c r}
\end{aligned}
$$

$\Phi$ is dimensionless transport, $C$ is the transport coefficient (between $8-12$ ), $\phi$ is angle of current and wave, $\theta_{m}$ and $\theta_{w}$ are Shields parameters for current and wave (Soulsby, 1997) and $\theta_{\beta c r}$ is the critical Shields parameter with slope correction. This dimensionless transport is then used to quantify the sediment transport rate, $Q_{b}$ as follows:

$$
Q_{b}=\Phi_{x}\left[g(s-1) D_{50}{ }^{3}\right]^{1 / 2}
$$

Here, $s$ is the relative density $\left(s=\rho_{s} / \rho\right)$ and $D_{50}$ is the median grain size. Then, the bed level change is represented as:

$$
\frac{\partial z_{b}}{\partial t}=-\frac{1}{(1-n)}\left(\frac{\partial Q_{b}}{\partial x}\right)
$$

where $z_{b}$ is the bed level, $t$ is the time and $n$ is porosity. Figure 7 shows the effect of this modification to the sediment transport formulation with greater mobilisation of sediment and the erosion extending further offshore. No elevated berm is predicted above the waterline, as would be expected.

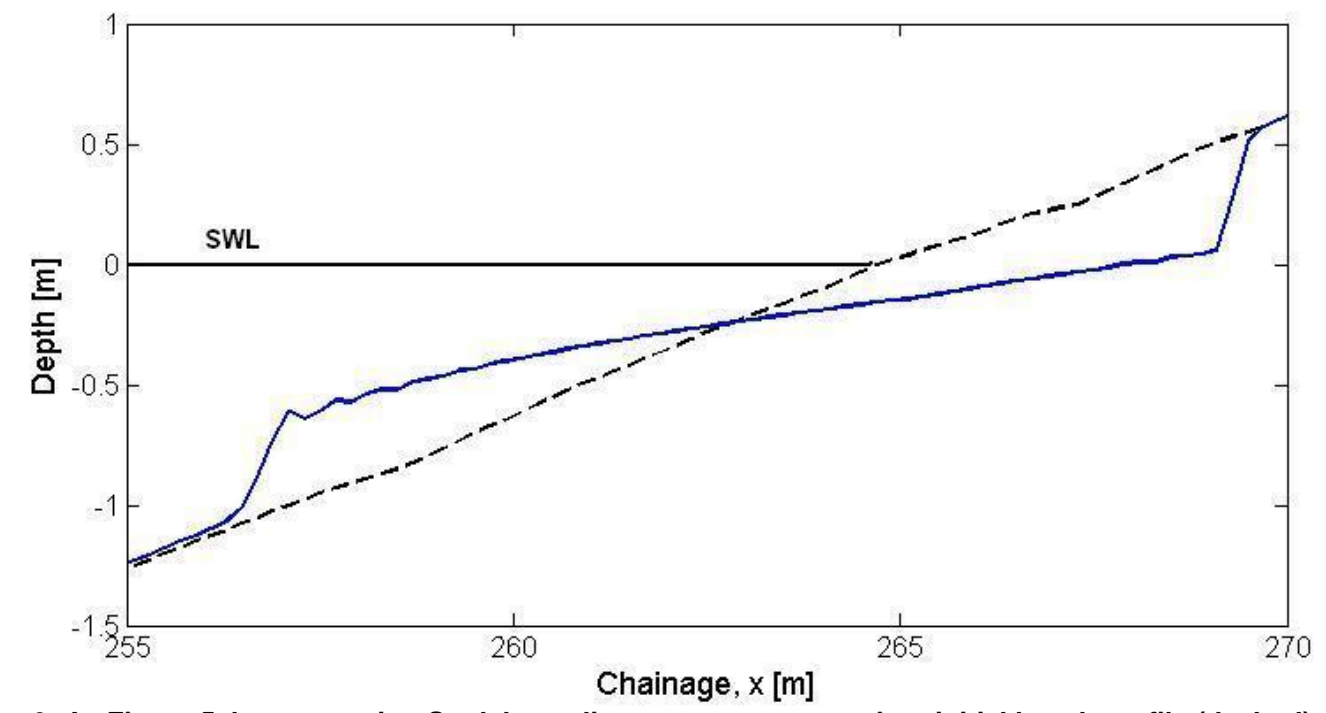

Figure 6: As Figure 5, but now using Soulsby sediment transport equation: initial beach profile (dashed); profile after 500 waves (blue).

\section{Lagrangian vs Eulerian Representation}

XBeach v12 drives sediment transport with the Lagrangian velocities, derived by correcting Eulerian velocity for Stoke's drift. This is done to account for return flow especially on dune erosion case as presented in Roelvink et al. (2009) and McCall et al. (2010). However under the swash over a steep gravel beach, including undertow or return flow in the process-based model is not significant (Pedrozo-Acuña et al, 2006). Thus, it is argued that the Lagrangian velocity calculated directly from NLSWE should be used. Tang et al. (2009) which used a similar type of model also used the velocity obtained from NLSWE to drive the sediment motion. The velocity profile envelope (figure 7) shows that the onshore and offshore velocity is now less asymmetric in line with expectation. 


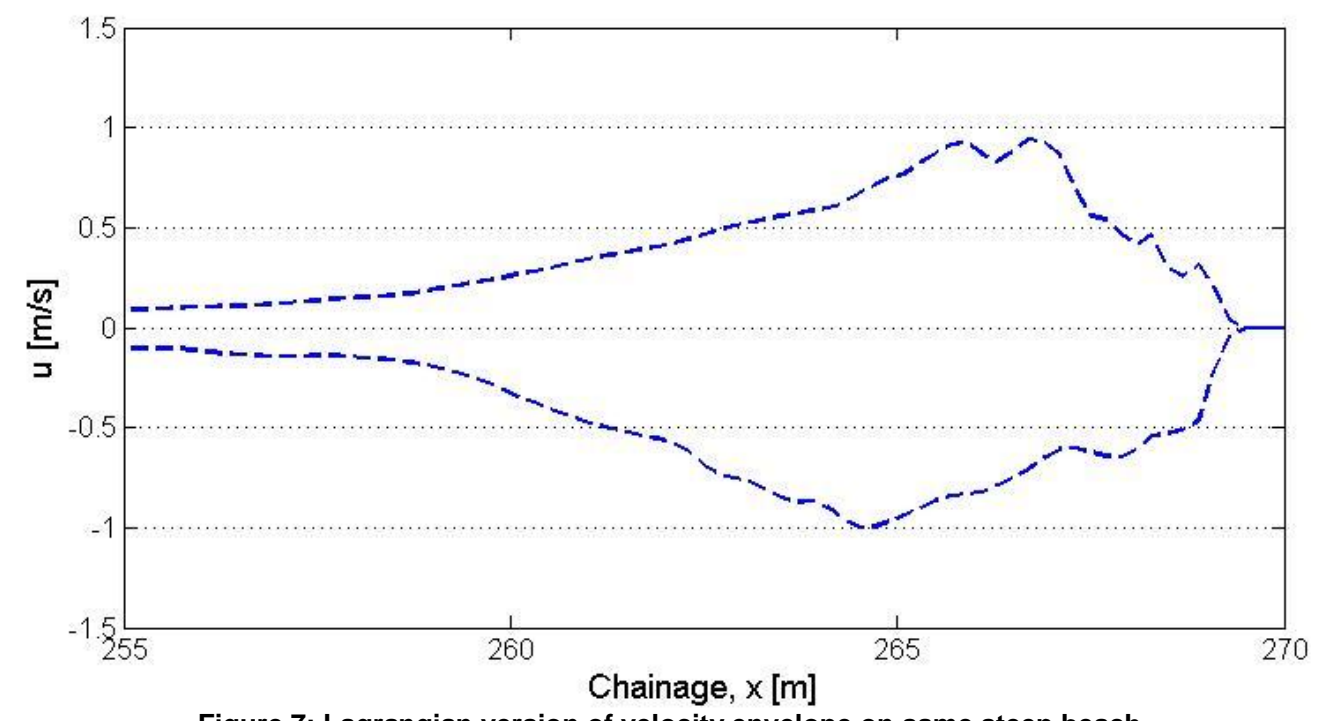

Figure 7: Lagrangian version of velocity envelope on same steep beach.

Indeed Figure 8 shows the resulting profile evolution, which still drives sediment offshore. However the volume changes are reduced. This appears to counteract the effect of the more satisfying Soulsby's sediment transport formulation.

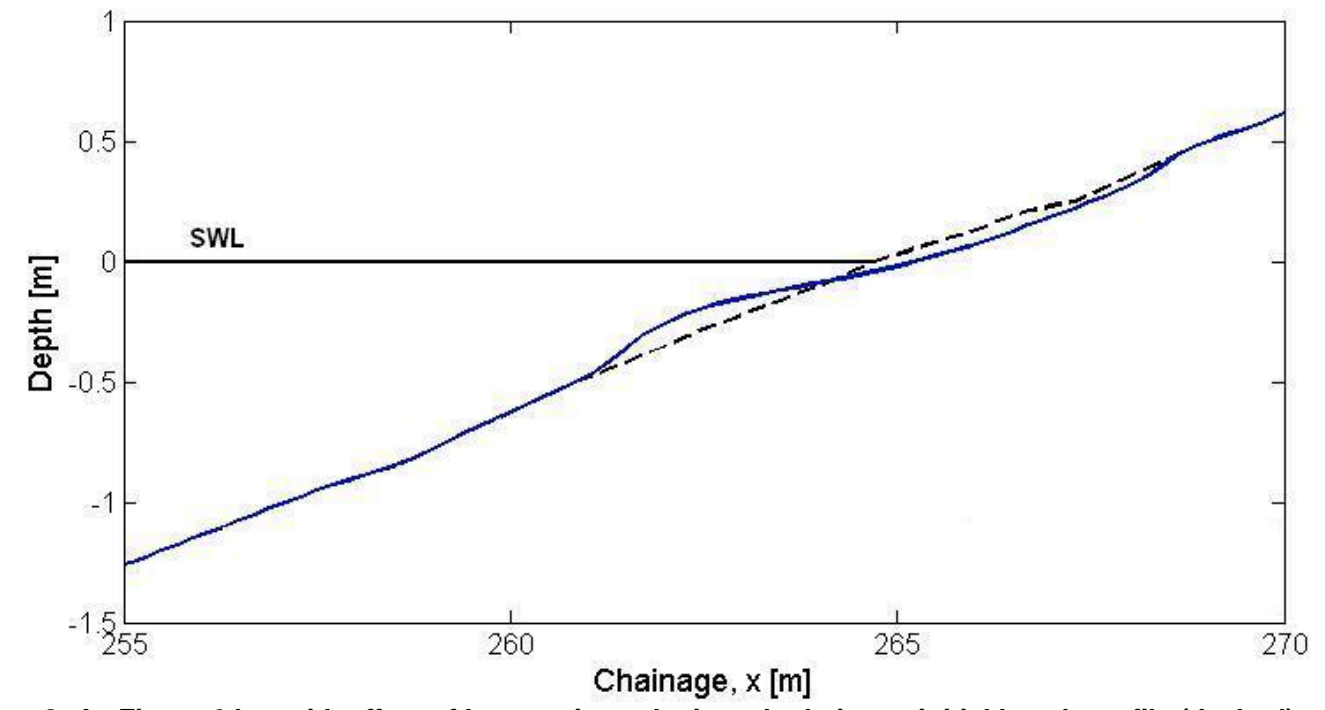

Figure 8: As Figure 6 but with effect of Lagrangian velocity calculations: initial beach profile (dashed); profile after 500 waves (blue).

\section{Inclusion of Infiltration}

Now we come to the most pertinent issue. As mentioned previously permeability has a critical effect on profile evolution on highly permeable beach. In particular, infiltration on the uprush reduces the strength of the backwash. Here, a simple formulation for infiltration is considered, whilst exfiltration is considered to have less impact on gravel beach and thus ignored. The technique used in the model is adapted from Packwood (1983). Karambas (2003) use the similar approach in his model to include in/exfiltration which incorporates the surface water model and groundwater model. Dodd et al. (2008) also used this technique to include infiltration in their model but without modelling the groundwater response, hence exfiltration was not considered. For completeness we repeat, here, an outline of Packwood's (1983) approach. In brief, an infiltration term $q_{f}$ is added to the 1DH NLSWE such that: 


$$
\begin{aligned}
& q_{f}=n \frac{\partial \zeta}{\partial t} \quad \text { (Unsaturated area) } \\
& q_{f}=0 \quad \text { (Saturated area) }
\end{aligned}
$$

where, $n$ is porosity and $\zeta$ is the depth of free surface inside the porous media (Figure 9). The depth of infiltration is calculated by the numerical integration of a one dimensional differential equation as shown in the following equation.

$$
n \frac{\partial \zeta}{\partial t}=K\left(1+\frac{h}{\zeta}\right)
$$

Where, $K$ is the permeability rate or hydraulics conductivity. There is a broad spectrum of possible values for $K$ reported in the literature. Table 1 shows several references for the range of $K$ values. Overall we can say that gravel can varies from 0.0001 to $0.1 \mathrm{~m} / \mathrm{s}$

Table 1. Various value of hydraulics conductivity for gravel

\begin{tabular}{|l|l|}
\hline Reference & Hydraulic conductivity $(\mathbf{m} / \mathbf{s})$ \\
\hline Foote et al. (2002) & $0.01-0.1$ \\
Heath (1983) & $0.001-0.08$ \\
Freeze and Cherry (1979) & $0.0001-0.1$ \\
\hline
\end{tabular}

By implementing this formulation, the flow model of 1DH NLSWE becomes:

$$
\begin{aligned}
& \frac{\partial \eta}{\partial t}+\frac{\partial h u}{\partial x}=-q_{f} \\
& \frac{\partial u}{\partial t}+u \frac{\partial u}{\partial x}-v_{h}\left(\frac{\partial^{2} u}{\partial x^{2}}\right)=-\frac{\tau_{b x}}{\rho h}-g \frac{\partial \eta}{\partial x}+\frac{F_{x}}{\rho h}-\frac{u q_{f}}{h}
\end{aligned}
$$

where $u$ is velocity in $x$-direction, $v_{\mathrm{h}}$ is horizontal viscosity, $t$ is time, $\rho$ is density of water, $h$ is water depth, $\tau_{b x}$ is the bed shear stresses, $g$ is the acceleration of gravity, $\eta$ is the water level and $F_{x}$ is the wave-induced stresses.

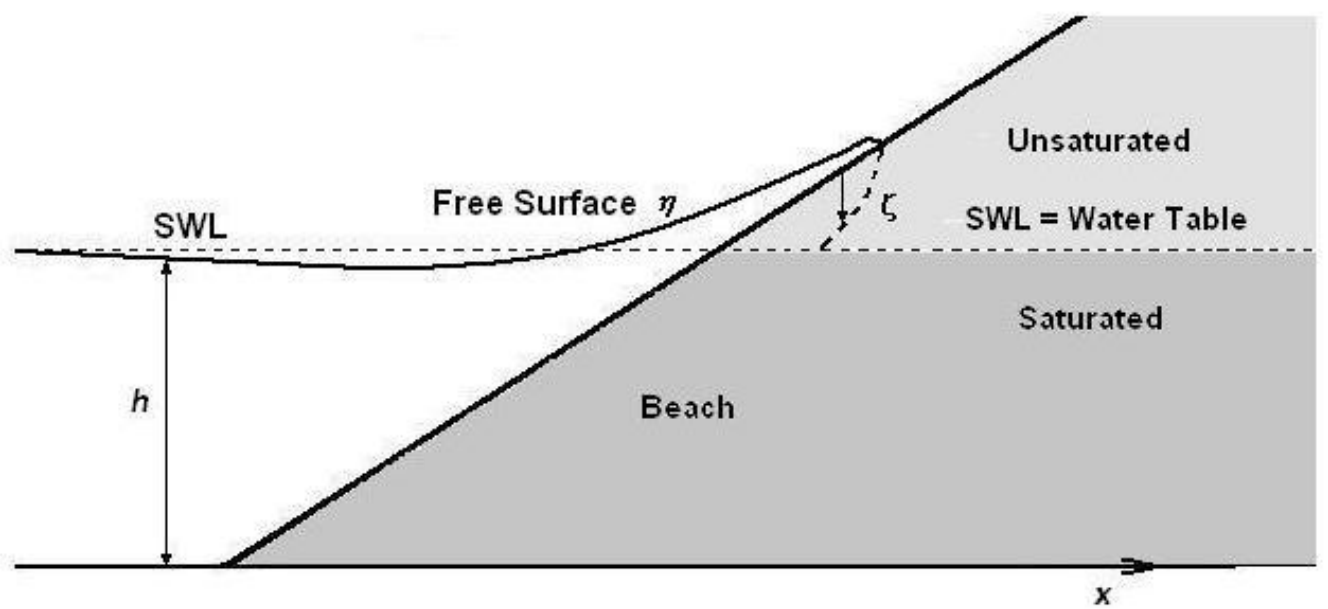

Figure 9: Schematic diagram of infiltration process.

As mentioned above, the approach to implementing infiltration is similar that of Dodd et al. (2008). The saturated and unsaturated boundary is referenced to the location of the still water line (SWL). Water is extracted from the fluid domain on the swash area above the SWL when the underlying bed is considered unsaturated and the area considered as wet. Thus, the mass of water is not conserved since neither groundwater nor exfiltration is included in the model. A sensitivity test was performed for this simulation with 3 permeability values of $K=0.005,0.02$ and $0.04 \mathrm{~m} / \mathrm{s}$, the results being shown in Figure 10. It was found that as the permeability increases, the berm becomes steeper and higher for similar durations of 
simulation. This happens because the runup shortens as the swash lens sinks more rapidly into the beach face, creating a more asymmetrical transport.

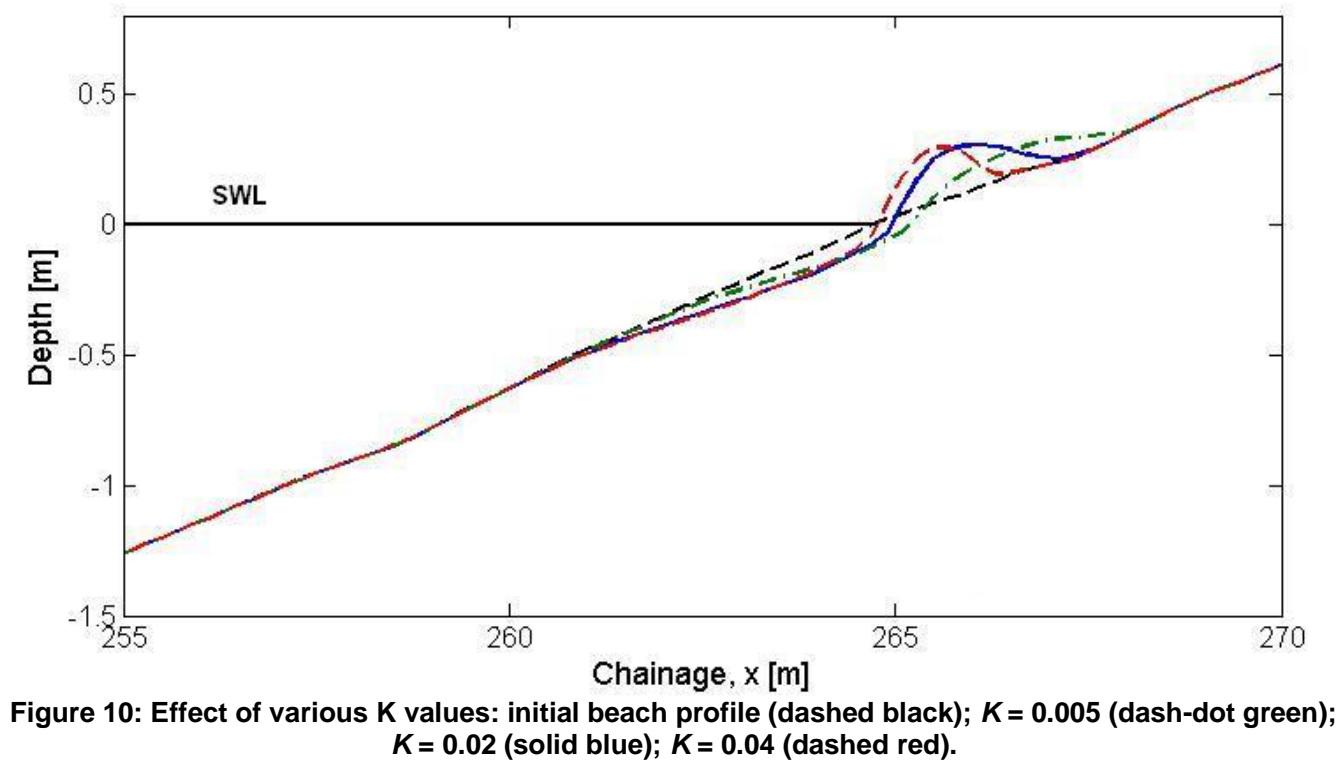

For the case of test $1 \mathrm{GWK}$, the most suitable $K$ value was found to be $0.02 \mathrm{~m} / \mathrm{s}$ as shown in figure 11 . In this simulation, the velocity envelope asymmetry is now biased onshore and hence sediment is transported towards the shore, above the water line where berm is formed in line with observations (Figure 12). The velocity predictions accord well with Masselink and Li (2001) who stated that infiltration causes a change in the velocity asymmetry that promotes onshore sediment movement for sufficiently high beach permeabilities. Therefore, by including the infiltration process in the model the expected beach development profile can be obtained for a gravel beach in its accretionary phase. The prediction can be made to agree very well with the laboratory observations in the GWK for 500 waves. Figure 13 also shows the comparison with Pedrozo-Acuña, (2006) results, although it should be noted that their results were not optimised for this particular case.

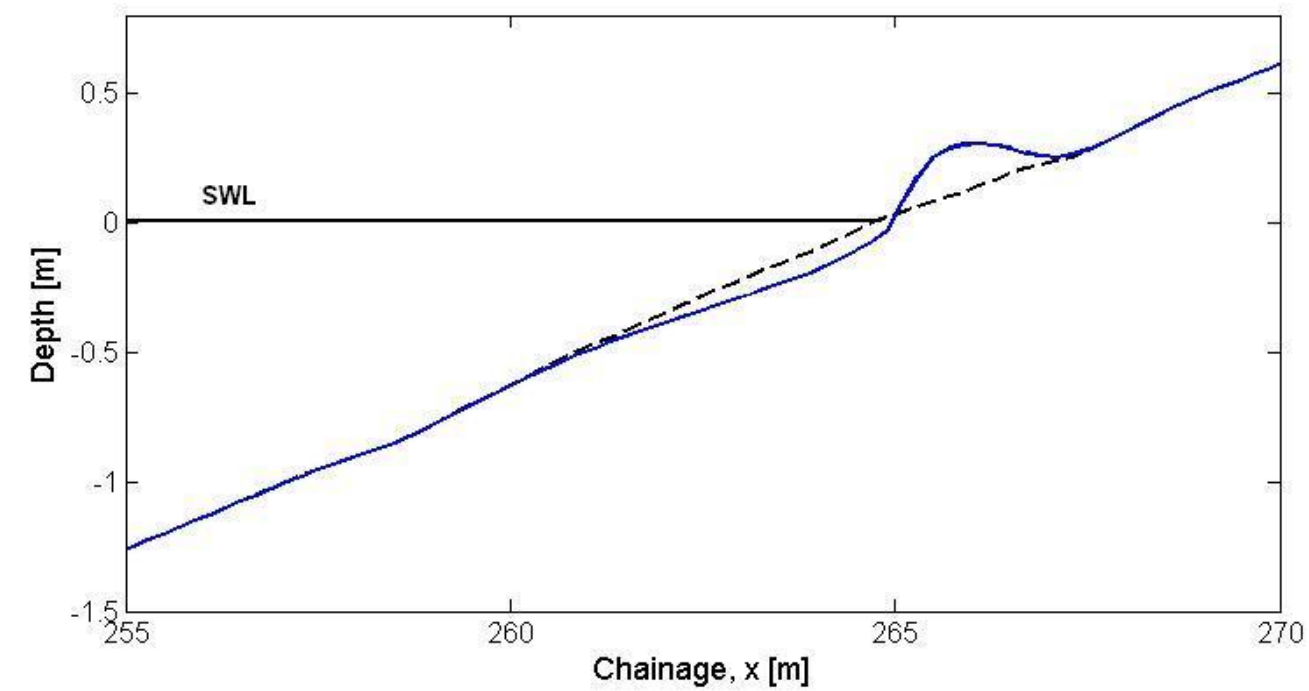

Figure 11: As Figure 8, but with infiltration added: initial beach profile (dashed); profile after 500 waves (blue). 


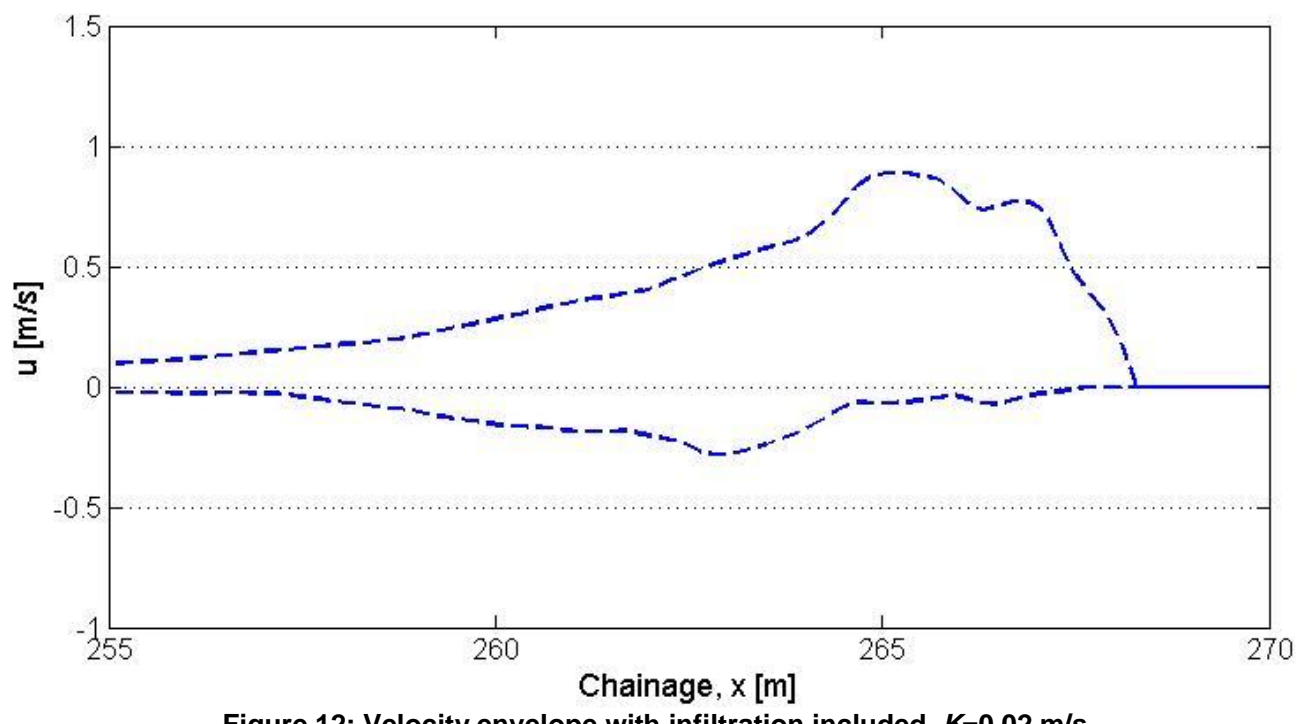

Figure 12: Velocity envelope with infiltration included, $K=0.02 \mathrm{~m} / \mathrm{s}$.

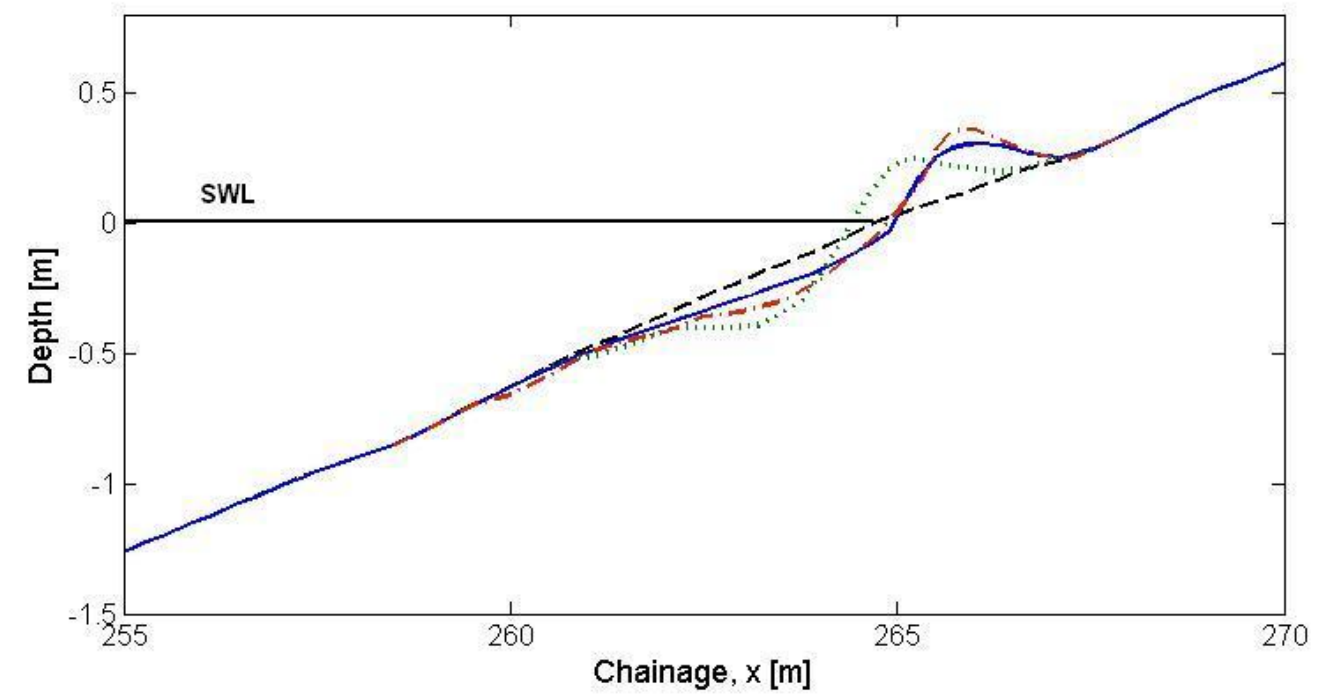

Figure 13: Comparison of results: final XBeach variant (blue); GWK (dash-dot red); Pedrozo-Acuña et al. 2006 results (dotted green); initial beach profile (dashed).

\section{CONCLUSION}

In conclusion, we have shown how the XBeach v12 public domain code was modified to enhance the predictive capability of gravel beach profile evolution, especially under accretionary conditions. The modifications made in the model comprise: introduction of new morphological module using Soulsby sediment transport equation for wave and currents (Soulsby, 1997); use of Lagrangian velocity for driving the sediment movement, in place of Eulerian velocity; incorporation of infiltration in the unsaturated area of the swash from the effect of permeability (adapted from Packwood, 1983). It was shown that on gravel beaches, infiltration is a significant process that needs to be considered in numerical studies in order to obtain the correct behaviour of profile development. The results obtained from this model agree well with the data from the GWK experiment and improve upon the results published by (Pedrozo-Acuña et al., 2006) for this test.

Whilst the agreement with the laboratory test is promising, further validation against an extended set of experiments is planned, also to include field data comparisons. The validated model will then be used to investigate further aspects of gravel coarse beach dynamics. 


\section{ACKNOWLEDGEMENTS}

The large scale tests in the Large Wave Channel (GWK) of the Coastal Research Centre (FZK) were supported by the European Community under the Access to Research Infrastructures action of the Human Potential Programme (contract HPRI-CT-1999-00101).The authors would like to acknowledge the above project for the data provided to be used in this paper.

The authors are also grateful for discussions with Dr. Adrián Pedrozo-Acuña of National Autonomous University of Mexico (UNAM) and Robert McCall of Deltares, Netherlands.

Mohamad H. Jamal is grateful to the Malaysian Government and Universiti Teknologi Malaysia for sponsorship of his research studies at the University of Plymouth, United Kingdom.

\section{REFERENCES}

Austin, M. J. 2005. Swash, groundwater and sediment transport processes on a gravel beach, $\mathrm{PhD}$ thesis, Loughborough University, U.K

Butt, T. and Russell, P. 2000. Hydrodynamics and cross-shore sediment transport in the swash-zone of natural beaches: A review, Journal of Coastal Research, 16 (2), 255-268.

Butt, T., Russell, P., Turner, I. L. 2001. The influence of swash infiltration-exfiltration on beach face sediment transport: Onshore or offshore?, Coastal Engineering, 42 (1), 35-52

Dodd, N., Stoker, A.M., Calvete, D., Sriariyawat, A. 2008. On beach cusp formation, J. Fluid Mechanics, 597, 145-169

Elfrink, B. and Baldock, T. 2002. Hydrodynamics and sediment transport in the swash zone: a review and perspectives, Coastal Engineering, (45), 149-167

Foote, M., Horn, D., Li, L. 2002. Measuring swash zone hydrodynamics and morphodynamic change - a high-resolution laboratory system using digital video, Journal of Coastal Research, SI 36, 300-316

Freeze, R.A. and Cherry, J.A. 1979. Groundwater, Prentice Hall Inc., Englewood Cliffs, NJ, USA

Heath, R.C. 1983. Basic groundwater hydrology, US Geological Survey Water Supply paper, 2220

Karambas, T. V. 2003. Modelling of infiltration-exfiltration effects of cross-shore sediment transport in the swash zone, Coastal Engineering Journal (JSCE), 45 (1), 63-82

Lawrence, J. 2005. Cross-shore morphodynamics of coarse grained beaches and beach/structure interaction: Numerical modelling and large scale measurements, $\mathrm{PhD}$ thesis, University of Plymouth, U.K

López de San Román-Blanco, B. 2003. Dynamics of gravel and mixed, sand and gravel beaches", PhD Thesis, Imperial College, University of London, London, UK

López de San Román-Blanco, B., Coates, T. T., Holmes, P., Chadwick, A. J., Bradbury, A., Baldock, T. E., Pedrozo-Acuña, A., Lawrence, J., Grüne, J. 2006. Large scale experiments on gravel and mixed beaches: Experimental procedure, data documentation and initial results, Coastal Engineering, 53, 349 $-362$

Masselink, G. and Li, L. 2001. The role of swash infiltration in determining the beachface gradient: a numerical study, Marine Geology, 176, 139-156

McCall, R.T., Van Thiel de Vries, J.S.M., Plant, N.G, Van Dongeren, A.R., Roelvink, J.A., Thompson, D.M., Reniers, A.J.H.M. 2010. Two-dimensional time dependent hurricane overwash and erosion modeling at Santa Rosa Island, Coastal Engineering, 57, 668-683

Packwood, A. R. 1983. The influence of beach porosity on wave uprush and backwash, Coastal Engineering, 7, 29-40

Pedrozo-Acuña, A. 2005. Concerning swash on steep beaches, PhD thesis, University of Plymouth, U.K

Pedrozo-Acuña, A., Simmonds, D. J., Otta, A. K., Chadwick, A. J. 2006. On the cross-shore profile change of gravel beaches, Coastal Engineering, 53, $335-347$

Powell, K.A. 1990. Predicting Short Term Profile response for shingle beaches, Report SR 219, HR Wallingford, Oxfordshire, UK

Reeve, D. E., Chadwick, A. J. and Fleming, C. A. 2004. Coastal Engineering Processes, Theory and Design Practice, Spon Press, London

Roelvink, J.A, Reniers, A., van Dongeren, A., van Thiel de Vries, J., McCall, R., Lescinski, J. 2009. Modelling storm impacts on beaches, dunes and barrier islands, Coastal Engineering, 56, 1133-1152

Soulsby, R.L. 1997. Dynamics of Marine Sands, Thomas Telford, HR Wallingford, London, U.K 
Tang, H.S., Keen, T.R., Khanbilvardi, R. 2009. A model-coupling framework for nearshore waves, currents, sediment transport, and seabed morphology, Communications in Nonlinear Science and Numerical Simulation, 14 2935-2947

Van Thiel de Vries, J. 2009. Dune erosion during storm surges, PhD thesis, Deltares, Netherland 